\title{
MARKET VALUE IMPACT OF JOINT VENTURES: THE EFFECT OF INDUSTRY INFORMATION-PROCESSING LOAD
}

\author{
RAVINDRANATH MADHAVAN \\ JOHN E. PRESCOTT \\ University of Pittsburgh
}

\begin{abstract}
Previous studies of the market value impact of announcements of joint ventures have not considered industry effects. We suggest that the impact of such announcements varies with the information-processing load associated with analyzing events in the relevant industry. An event study analysis based on a stratified sample of 108 announcements in three industry groups, one with a light, one with a moderate, and one with a heavy information-processing load, confirmed this hypothesis. We examine implications for a signaling perspective on joint venture announcements.
\end{abstract}

Joint ventures are collaborative interfirm arrangements involving either equity participation by the partners in a new entity, one firm's taking an equity position in another, or joint ongoing manufacturing or marketing activity (cf. Harrigan, 1985). A growing number of researchers have studied several aspects of joint ventures, including motives (Oliver, 1990), benefits (Harrigan, 1985), interpartner learning (Hamel, 1991), and effects on stock value (e.g., Koh \& Venkatraman, 1991). By isolating the abnormal stockholder returns attributable to the announcements of joint ventures, researchers in the last stream have established that such announcements affect the market value of venture participants positively (Koh \& Venkatraman, 1991; McConnell \& Nantell, 1985). We sought to extend this line of inquiry by exploring whether the market value impact of joint venture announcements varies across industries. Even though it is widely accepted that environments moderate the strategy-performance relationship (Prescott, 1986) and that researchers investigating strategy need to control for industry effects (Dess, Ireland, \& Hitt, 1990), previous studies have not considered the effects of industry on the market value impact of joint venture announcements. We suggest that the market impact varies with the information-processing load faced

This research was supported by a Sloan Foundation research grant. We acknowledge the support of $\mathrm{I} / \mathrm{B} / \mathrm{E} / \mathrm{S}$ Inc. in providing access to the $\mathrm{I} / \mathrm{B} / \mathrm{E} / \mathrm{S}$ database. We are grateful to Robert Nachtman, Abdul Rasheed, Alice Stewart, Usha Ganesh, Devi Gnyawali, Vidhan Goyal, Glen Kidd, Balaji Koka, John Naman, and this journal's reviewers for their assistance at various stages of this research. 
by investors seeking to analyze relevant industry events. Specifically, we hypothesized that a U-shaped relationship exists between the degree of information processing required for an investment analyst to understand a joint venture and the venture's perceived market value. Thus, this article contributes to the literature by incorporating a cognitive perspective into the study of the market value impact of joint ventures.

\section{EMPIRICAL SUPPORT FOR POSITIVE MARKET VALUE IMPACT}

The reasoning that the benefits of joint ventures outweigh their costs is the premise for arguing that the announcement of a joint venture should increase the market value of the participating firms. If a joint venture does, in fact, hold the promise of strengthening a firm's strategic prospects, investors should view the firm's future performance in a positive manner. Given the assumption of an efficient capital market (Fama, 1976)-the premise that security prices reflect all available information-there must be a consequent positive impact on the stock price of the firm. This impact will be demonstrated by stockholder wealth creation through abnormal positive returns associated with the announcement of joint ventures. This reasoning is embodied in the event study approach that has been used to evaluate the stock market impact of joint ventures. Two points must be noted regarding this approach: First, a key issue in the stockholder wealth creation process, and one that is central to this study, is how the cognitive processes of investors affect their use of available information in evaluating joint venture announcements. For example, if investors face a very large amount of information, do they react in the same way as when there is a small or moderate amount of information? In other words, is the assumption of an efficient capital market valid in all situations? Second, several authors have discussed the limitations of the event study approach (see the Methods section) in the context of organizational research. However, given that most firms need to tap the market for funds, the investment community is a key stakeholder that both directly and indirectly influences managers' decision making, firms' incentive structures and designs, and the relationships among resource allocation decisions.

In their empirical investigation of the common stock returns of U.S. firms that participated in domestic joint ventures, McConnell and Nantell (1985) concluded that significant stockholder wealth gains resulted from joint venture announcements. From data on a sample of 136 joint ventures involving 210 firms from diverse industries, they inferred that joint venture announcements were, in fact, wealth-creating transactions for the shareholders of the participating firms.

More recently, Koh and Venkatraman (1991) examined the market value impact of joint venture formation in the information technology sector. Their sample consisted of 239 firms involved in 175 joint ventures over the period 1972-86. Joint ventures were shown to have a greater impact than technology exchanges, whereas licensing, marketing, and supply agreements did not have any significant impact. Further, joint ventures had 
significant, positive effects if they strengthened existing product-market segments or placed new products in existing markets, but not if they developed new customers or entered new, unrelated product-market segments. Finally, it was found that the relative sizes of the partner firms were key to the extent of market value impact: shareholders of the smaller partners earned significantly positive abnormal returns, but those of the larger partners earned insignificant abnormal returns.

\section{THE EFFECT OF INDUSTRY INFORMATION-PROCESSING LOAD}

Dess and colleagues (1990) noted that strategic management researchers have not consistently controlled for possible industry effects. Further, they suggested that researchers can gain additional understanding and insight regarding empirical results, as well as help in developing more accurate normative and descriptive theories, by including industry controls in their studies. Some studies have incorporated the effect of industry on joint venture formation and characteristics (e.g., Harrigan, 1988a), but research related to the market value impact of joint ventures has rested on the assumption that impact is invariant across industries. For instance, despite employing a multiindustry sample, McConnell and Nantell (1985) did not control for industry. By focusing on one sector of the economy, information technology, Koh and Venkatraman (1991) reduced the effect of environmental variation on their results. However, their definition of information technology was rather broad, including industries as diverse as electronic components, TV programming, and software.

As noted, we propose that the information-processing load associated with an industry significantly influences the way in which a market analyst reads and responds to joint venture announcements. The analysisdecision-action cycle can be described as follows: an analyst views a report, evaluates the information, decides if the implications are positive or negative, and accordingly buys, holds, or sells the relevant stock, thereby influencing its price. Quite clearly, the analyst's cognitive processes and limitations play a crucial role in this cycle. In assuming that stock prices reflect all available information, however, users of the event study method have neglected to take those cognitive elements into account. The present study is in accord with recent strategic management research, which holds that cognition plays a major role in strategic decisions (Eisenhardt \& Zbaracki, 1992).

\section{Industry Information-Processing Load}

Building on the literature related to information-processing load (Dunbar, 1981; Reger \& Huff, 1993), we posit the construct of industry information-processing load. The information-processing load associated with an industry will depend on the "multiplexity" of information-the presence of simultaneous signals that compete for attention-in the industry's environment and will determine the difficulty of analyzing the competitive impact of an industry event. Investors will find it easier to assess the 
consequences of an event when there is low information load because the cause and effect relationships among critical success factors can be more easily determined. Although it might seem that increasing levels of information will be associated with increasing formality of analysis, cognitive psychologists have concluded that the amount of information processed under varying information-processing loads actually follows an inverted U-shaped curve (Taylor, 1984). When the information-processing load is light, decision makers process low amounts of information; when it is moderate, they process the highest amount of information; and when the information-processing load is heavy, they exhibit signs of cognitive strain (Taylor, 1984) and revert to processing low amounts of information. This finding has been reinforced in a variety of decision settings (e.g., Eisenhardt \& Zbaracki, 1992).

Miller's (1956) finding that people cannot hold more than about seven "chunks" of information in their minds at a time forms the basis for the construct of information-processing load. Simon (1957) carried this argument further by suggesting that the human mind can deal with only a limited amount of information in any given period of time. This cognitive limit leads to information overload on the part of a decision maker (Dunbar, 1981; Reger \& Huff, 1993). The information-processing load associated with a situation is a good indicator of the kind of analysis that would be undertaken in that situation (Eisenhardt \& Zbaracki, 1992). Weick (1970) suggested that people respond to information overload by employing "disengaging" strategies that help to balance perceived information-processing demands with perceived information-processing capabilities. For example, one disengaging strategy might be to emphasize past, rather than current, information-processing demands by focusing on completing ongoing projects (Dunbar, 1981; Weick, 1970). Similarly, Tversky and Kahneman (1974) demonstrated that people rely on decision heuristics to reduce complex tasks to simpler judgmental operations. It has been repeatedly observed that people respond to highly complex and uncertain situations by attempting to simplify them (Reger \& Huff, 1993). For lighter informationprocessing loads, causal linkages and means-ends relations are clear, and extensive analysis may not be necessary-choices can be effectively made through the application of principles (Ghemawat, 1991). As the information-processing load increases, decision makers increasingly turn to more formal and sophisticated analyses (Flynn, 1990). Thus, large, integrated databases and analytical systems will be relied upon in environments in which uncertainty is at a moderate level (Fredrickson, 1984). However, beyond some threshold, formal approaches begin to lose their utility, and decision makers rely more on informal discussions, patterns of past experience, and decision heuristics (Flynn, 1990; Tversky \& Kahneman, 1974).

We propose that the general notion of information-processing load can be meaningfully applied to industries. The information-processing load associated with an industry reflects the quantity and nature of relevant information and determines the difficulty of analyzing the competitive im- 
pact of an industry event. Industry information-processing load is hypothesized to influence investor response to joint venture announcements as follows: If investors like what they see in proposed arrangements, they will buy or recommend the stock of the partner firms, thereby driving prices up and creating shareholder wealth. The core of our argument is that the investment community's ability to clearly perceive the potential benefits of a joint venture is a key element in this process. If joint ventures are beneficial in general, investors' ability to perceive the potential benefits of a particular joint venture will depend on the information-processing load in the relevant industry. The result may be that the venture's benefits, though potentially present, are not sufficiently clear to justify an enthusiastic response. In industries with light information-processing loads, investors will find it relatively easy to anticipate a joint venture's impact and will respond positively. In industries with moderate loads, investors will attempt to formally assess a venture's potential impact, and the inherent difficulty of the formal analysis will dampen immediate investor response. Finally, in industries with heavy information-processing loads, it may be so difficult to assess potential benefits analytically that investors will use simplifying assumptions ("joint ventures are bound to be helpful") and respond positively. Thus,

Hypothesis 1: The abnormal stock market returns associated with joint venture announcements in industries with light and heavy information-processing loads will be more positive than the abnormal returns associated with joint venture announcements in industries with moderate information-processing loads.

\section{METHODS}

The standard event study methodology was used to measure the strength of investor response to joint venture announcements. This method has been widely used both in research on finance (e.g., McConnell \& Nantell, 1985) and research on strategy (e.g., Davidson \& Worrell, 1992). The method has its limitations (Bromiley, Govekar, \& Marcus, 1989), especially regarding departures from the capital market efficiency assumption, such as overreaction to events and size effects. Further, it has been criticized as being inappropriate for evaluating incremental change, anticipated change, and the impact of past events (Bromiley et al., 1989). However, the event study method provided us with a well-accepted way of testing differences in investor response to joint ventures across industries; the assumption that stock market reaction presages the actual success or failure of a joint venture was not necessary. We summarize the method here; a detailed exposition can be found in Dodd and Warner (1983). Event study employs a market model to estimate the abnormal returns accruing to a shareholder consequent upon a specified event. Daily market model parameters are estimated for a firm using 45 days' returns, from 60 days be- 
fore the event $(t-60)$ to 15 days before it $(t-15)$, and the formula $R_{i t^{\prime}}=$ $a_{i}+b_{i} R_{m t}+e$, where $R_{i t^{\prime}}$ is the expected stock return of firm $i$ on day $t$, $R_{m t}$ is the rate of return on a value-weighted index on day $t, a_{i}$ and $b_{i}$ are ordinary-least-squares estimates of market model parameters, and $e$ is the error term. The 45-day period over which the parameters are estimated is referred to as the estimation period.

The abnormal return is the difference between the actual return during the event period and the return predicted using the market model. Thus, $R_{i t}=R_{i t^{\prime}}+P E$, where $R_{i t}$ is the actual return during the event period and $P E$ is the prediction error, which is assumed to represent the market value impact of the announcement. We used the test statistics described in Dodd and Warner (1983) to determine if the prediction error was significantly different from zero.

A key issue in the event study method is the choice of the event period, an issue that has been extensively discussed (Bromiley et al., 1989; Lubatkin \& Shrieves, 1986). The event period, or announcement period, is the period over which the impact of the announcement on the security's price is measured. Many authors have used a two-day period consisting of the day prior to an announcement and the announcement day itself. Taking a conservative approach that accounts for possible information leakage before, during, and after the formal announcement of an event as well as for delays in processing information, we examined the market response over several time frames, including the standard two-day window.

\section{Design}

In considering different methods of controlling for industry effects, Dess and colleagues (1990) suggested that stratified sampling by industry is generally appropriate to the complex nature of strategic management research. As this suggestion was relevant to our hypothesis, we adopted a stratified sampling design in which we chose six industry samples, two characterized by light information-processing loads, two by moderate loads, and two by heavy loads.

\section{Indicator of Industry Information-Processing Load}

Industry information-processing load was measured as the standard deviation among earnings forecasts made by institutional brokers (O'Brien, 1990). These brokers and other analysts publish their estimates of how major firms will perform at the end of a given quarter. The brokers' estimates are available in the I/B/E/S data bank (Institutional Brokers Estimate System, 1992). Typically, a number of earnings forecasts will be available for each firm in each quarter, with each forecast coming from a different analyst. We argue that the standard deviation among the earnings forecasts made by analysts can be averaged over the firms in an industry to yield a proxy for industry information-processing load. Previous research has shown that analysts do not vary significantly from each other in ex post forecast accuracy (O'Brien, 1990). Thus, there is no reason to believe that 
a high standard deviation among analysts' forecasts can be attributed to individual differences. Further, we can safely conclude that the analysts represented in the I/B/E/S data are experts on their own industries and that they are, by and large, equally well-informed on the latest developments in the industry they analyze. It has been shown, however, that the diversity of analysts' options increases as private information increases (Barry \& Jennings, 1992). Thus, an industry in which the estimates diverge less from each other ought to be characterized by reasonably equal access to public information and a lighter information-processing load. Similarly, estimates relating to a heavy information-processing-load industry can be expected to diverge more-thus leading to a high standard deviation. We averaged the reported standard deviations over an industry's firms over 1976-91 to arrive at the industry standard deviation. The 268 industries in the database were then sorted in ascending order of these standard deviations, allowing us to identify industries with light, moderate, and heavy information-processing loads.

The standard deviation of earnings forecasts ranged from 0.06 to 3.6 , with a mean value of 0.72 and a standard deviation of 0.38 . We chose 0.53 as the cutoff for light information-processing load (mean minus half standard deviation) and 0.91 as the cutoff for heavy information-processing load (mean plus half standard deviation). Visual inspection of the data indicated that these levels offered good breaks, with the low and high areas being sufficiently different from the mean but not so far away as to be virtual outliers. Having sorted the industries into three groups, we randomly selected the six industries included in the analysis within the constraints of two criteria: (1) they should be declining or maturing (see the section on controls below) and (2) there should be a reasonable probability of our finding a sufficient number of joint ventures to satisfy the requirements of the event study method. For example, we did not consider shipbuilding or the tobacco industry because it was unlikely we would find enough joint ventures. Further, the oil industry, in which most projects are undertaken as joint ventures, was screened out, because investors might not respond to such frequent ventures in the same way they would respond in industries in which they are more infrequent. The sampled industries were as follows: machinery (general and industrial) and retail sales in the light information-processing-load category, both having a standard deviation of earnings forecasts of 0.51 ; the automobile and computer (mainframe and minicomputer) industries in the moderate category, with standard deviations of 0.82 and 0.77 , respectively; and, the aluminum and steel industries in the heavy information-processing-load category, with standard deviations of earnings forecasts of 1.86 and 1.18 , respectively.

Since information-processing load is associated with the amount and variety of material (Smith \& Grimm, 1991) and not simply with the uncertainty that an investor needs to deal with, we developed three proxies for industry information-processing load. The first is the number of reports indexed to each of the six industries in the Dow Jones News Retrieval Service over 1989-94, divided by the number of establishments in that in- 
dustry reported in the 1991 Statistical Abstract of the United States and in the 1992 Manufacturing USA. The Spearman rank-order correlation for the six industries using the I/B/E/S-based measure and the first proxy was 0.93. The second proxy measured size, which has been shown to be related to complexity and thus information-processing demands (Baker \& Cullen, 1993). For each industry, we calculated the ratio of number of employees to number of establishments, using data drawn from the same volumes of the Statistical Abstract and Manufacturing USA, as a normalized measure of size. The Spearman rank-order correlation for the six industries using the I/B/E/S-based measure and the second proxy was 0.93 . For the third proxy, our logic was as follows: industries that receive inputs and send outputs to few other industries are more self-contained and likely to be vertically integrated (Maddigan, 1981), and high levels of vertical integration will be associated with high levels of information processing. Thus, the more industries with which a focal industry has dealings, the lighter its information-processing load should be. We counted the number of industries from which each of our focal industries received inputs and to which it sent outputs using data drawn from the 1982 Benchmark Input-Output Accounts of the United States. The Spearman rank-order correlation for the six industries using the I/B/E/S-based measure and this third proxy was 0.67 and was in the hypothesized direction. Given the small sample, significance tests were not appropriate in any of the three cases. The proxy measures suggest that our measure of industry information-processing load has validity.

\section{Controls}

The research design employed two levels of controls. The first was an industry-level variable, since it is possible that joint ventures are either not equally valuable in all industries or that the life cycle of an industry influences the rate of formation of joint ventures. From among the life cycle categories used by Auster (1992), we chose maturing-declining industries, a group in which joint ventures are of less value, according to Auster (1992: 782-783). If that conjecture is correct, our choice of a sample from maturing and declining industries should have led to a conservative test of our hypothesis. There were no reasons to believe that the industries sampled differed substantially from each other in terms of the inherent value of joint ventures or their patterns of formation. All six industries have been described as declining or maturing over the last decade (e.g., Auster, 1992; Harrigan, 1988b).

A second control was for firm size, since research (e.g., Koh \& Venkatraman, 1991) has found that smaller partners exhibit larger abnormal returns than their larger counterparts.

\section{Data}

Koh and Venkatraman (1991) found that different types of alliances were associated with different levels of investor response, but restricting 
the sample to joint ventures eliminated the influence of alliance type. We defined joint ventures as arrangements that involved either equity participation by the partners in a new entity, one partner's taking an equity position in the other, or ongoing manufacturing activity, marketing activity, or both, between partners (cf. Harrigan, 1985). Thus, such arrangements as R\&D partnerships, cross-licensing, and pure franchising were screened out.

The announcement dates and descriptions of the joint ventures in the sample industries were obtained from the Wall Street Journal index and Mergers \& Acquisitions for the years 1978-91. We screened the announcements to ensure that (1) no two events occurred during the announcement period, (2) there were no announcements of joint ventures during the estimation period, and (3) there were no other major announcements during the event period. The final sample consisted of 108 joint ventures, with 36 in the industries with light information-processing loads, 36 in moderate information-processing-load industries, and 36 in heavy-information-processing-load industries. The mean sales of sampled firms was $\$ 1.6077$ billion (s.d. $=\$ 2.1334$ billion); the sales figures ranged from $\$ 0.277$ billion to $\$ 9.2542$ billion (in constant $1983-84$ dollars). Forty-one ventures involved the creation of a new entity, 11 involved the taking of an equity position by one partner in the other, 60 involved ongoing production and marketing, and 37 involved ongoing marketing and service provision (the categories are not mutually exclusive). An example of a production joint venture in the steel industry (heavy information-processing load) is one between Nucor and Oregon Steel Mills in which they built a $\$ 400$ million minimill to make sheet steel in the Pacific Northwest. A marketing-related example from the retail industry (light informationprocessing load) is Walmart's agreement to join forces with Cullum Company to build large combination grocery and general merchandise stores. An example of the formation of a new entity in the computer industry (moderate information-processing load) is NCR and Teradata corporations' formation of a joint venture to make parallel processor computers.

Daily returns data were obtained from the Center for Research in Security Prices (CRSP) database.

\section{RESULTS}

Table 1 shows the results of tests of significance between the estimated abnormal returns associated with joint ventures in the light, moderate, and heavy information-processing-load industries. Since we had hypothesized that the abnormal returns in industries with light and heavy informationprocessing loads would be more positive than those in industries with moderate information-processing loads, we compared returns for both the low and high groups with those for the middle group. We compared returns by calculating the difference between them and testing it for signif- 


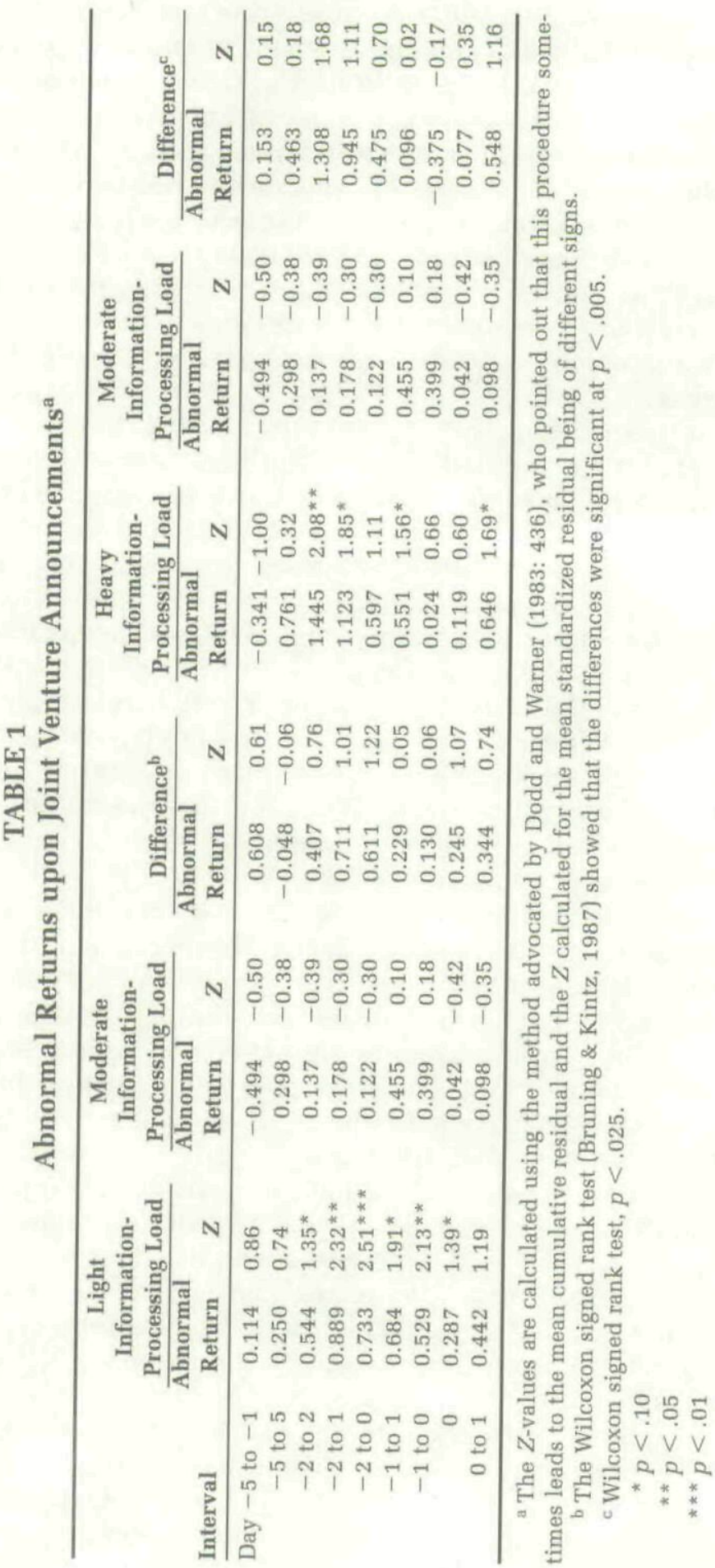


icance. Davidson and Worrell (1992) used this method to test for differences between the market value impacts of different types of automobile industry product recalls. We used Wilcoxon signed rank test, a nonparametric test for differences between samples (Bruning \& Kintz, 1987), to test for significant differences in abnormal returns; each time period was treated as an observation from a sample and results compared across information-processing-load groups. Results indicate a significant difference $(p<.005)$ between the returns for the light and moderate information-processing-load industries. Similarly, there is a significant difference $(p<.025)$ between the returns for the industries with heavy and moderate information-processing loads. The results thus support our industry effects hypothesis.

Figure 1 presents the results graphically. Since the hypothesis was that abnormal returns for industries with light and heavy information-processing loads would be more positive than those for moderate informationprocessing-load industries, we expected a U-shaped curve on plotting abnormal returns against industry information-processing load. As Figure 1 shows, this expectation was confirmed.

Additional post hoc tests further reinforced our conclusion. We combined the low and high information-processing subsamples and tested for the difference from the medium subsample. The Wilcoxon signed rank test showed that the difference was significant $(p<.005)$. Although we hypothesized no difference between the low and high subsamples, we tested for such a difference, finding that it was not significant. This result confirms our expectation that investors respond similarly in light and heavy information-processing-load industries.

Three separate analyses were undertaken to examine the possible effect of firm size. First, we tested the effect of absolute size by dividing each industry subsample into large and small groups using median sales (in 1983-84 dollars) to set cutoffs and then combining the small and large groups into overall groups comprising half the sample. The Wilcoxon signed rank test revealed no significant difference between the abnormal returns of the small and large groups. Second, within each industry information-processing-load group, we again split the sample into small and large groups on the basis of median sales. We then compared the abnormal returns for each subgroup and found that they conformed to the U-shaped pattern shown by the combined sample in Figure 1. Third, since it has been found that the smaller of two partners enjoys a more positive market reaction than the larger partner in a joint venture (e.g., McConnell \& Nantell, 1985), we examined the sample to determine the sizes of the partners. In constructing our sample, we included the returns only of the first-named partner in each joint venture, which is an appropriate sampling technique for event study research (e.g., McConnell \& Nantell, 1985). However, we compiled size data on both partners, allowing us to determine their relative sizes. In six cases, the partner in our sample was the smaller partner. We recalculated the analysis without the six small partners and 


\section{FIGURE 1}

\section{Abnormal Returns on Joint Venture Announcements}

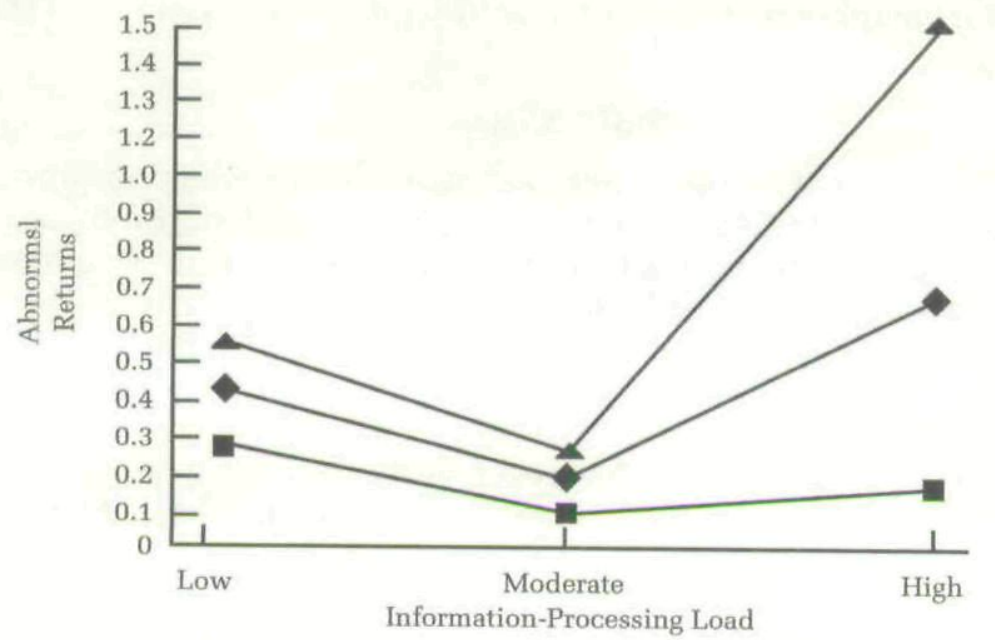

Day 0

Day 0 to Day 1

- Day -2 to Day 2

found no significant differences from the original analysis. Thus, the size effect does not appear to be a potential confounding factor.

An additional analysis was conducted to test for the effects of the degree of product-market relatedness of the joint ventures. We used a procedure similar to that of Koh and Venkatraman (1991) to classify each joint venture as either related or unrelated in product-markets and technologies. The results indicated that 104 of the 108 joint ventures were related to core products, markets, or technologies of the parent firm. Three ventures were unrelated, and one remained unclassified as a result of data limitations. Thus, the sample was homogeneous in terms of the degree of relatedness. As a check on the original results, we recalculated the event study analysis excluding the four unrelated and unclassified ventures and found no differences.

To address any concern about the representativeness of our sample, we analyzed the abnormal returns in the sample as a whole. The results indicated that joint venture announcements in all six industries in the sample were associated with significant abnormal returns. Our analysis showed that the average prediction error over the two-day announcement period (representing the gain in market value attributable to the announcements of the joint ventures) was 0.395 percent and that the null hypothesis that an announcement had no effect could be rejected at the .1 
level of significance. In general, the market reaction was significant at the .05 level for the periods day -2 to day 1 and day -1 to day 1 , and at the .1 level for the periods day -2 to day 2 , day -2 to day 0 , and day -1 to day 0 . In view of the conclusions of previous research, these results confirm that our sample was representative of joint venture announcements in general.

\section{DISCUSSION}

We predicted that in industries with moderate information-processing loads the market value impact of announcements of joint ventures will be lower than it will be in industries with either light or heavy information-processing loads, thereby highlighting the role of cognitive factors in how investors evaluate joint venture announcements. Our results point to the conclusion that the information-processing load associated with an industry has an effect on investor response to joint venture announcements and should be considered in future event studies.

Before we turn to how market signaling can be used to address information-processing-load issues, we note three limitations of this research and directions for future study. A basic assumption of this study is that analysts understand the firms they monitor. However, an alternative hypothesis is that the value of a joint venture may be difficult to assess if it is designed to enhance or combine capabilities or routines whose synergistic effects are not easily understood by analysts (Harrison, Hitt, Hoskisson, \& Ireland, 1991). A second limitation is the possibility that information-processing loads vary across strategic groups within an industry. A final limitation regards the sample's being confined to mature and declining industries and whether results would generalize to emerging and growth industries. Although these limitations are valid and warrant future study, managers who adopt a signaling perspective on joint venture announcements may be able to address the associated concerns.

\section{Joint Venture Announcements as Signaling}

There is a developing body of literature on signals, defined as "announcements. . . intended to convey information" (Heil \& Robertson, 1991), in the fields of economics (e.g., Spence, 1974), finance (e.g., Brennan \& Kraus, 1987), and strategy (e.g., Heil \& Robertson, 1991). The view that joint venture announcements are signals to investors is implicit in the event study method. However, few researchers have applied the idea of signaling to the study of the market value impact of announcements. We suggest that this would be a fruitful direction for research.

The major benefit stemming from applying a signaling perspective to joint ventures would be a richer understanding of the process of investor reaction to market events. Crucial to this process, of course, are the cognitive attributes and limitations of individual investors, which have hitherto not been part of the market value impact framework. Announcing a joint venture allows managers to both convey information to the invest- 
ment community and receive feedback from analysts as to the value they place on the joint venture. However, if the signaling between managers and analysts is not clear as a result of problems at either end, the possibility of useful feedback is reduced. We contend that as the information-processing load increases, so does the possibility that the intent of a joint venture is not immediately clear. Current event study research has not gone beyond investigating the broad association between specific events and investor response, perhaps because of methodological constraints. Taking a signaling approach based on what is known about human cognitive processes and limitations would force research attention onto moderating variables such as sender, signal, and receiver characteristics and firm, market, and industry characteristics (Heil \& Robertson, 1991).

Studies by Higgins and Bannister (1992) and Higgins and Diffenbach (1989) have underscored the importance of communicating strategy to stockholders. This research suggests that corporations' communication of strategy to the financial community affects share prices. A survey showed that a growing number of firms devote a significant portion of their corporate advertising budgets to communicating corporate strategy (Higgins \& Diffenbach, 1989). Respondents to the same survey also noted that strategy messages and communication media must be tailored to specific target audiences. In addition, the current research has shown that firms need to take industry information-processing loads into account when communicating strategy to the financial community.

Viewed in this light, our results suggest that joint venture announcements do not have the same signaling characteristics in all industries. Managers in industries associated with moderate and heavy information-processing loads may need to take extra precautions if they want their audiences to fully appreciate the impact of announced events. In an industry with a moderate information-processing load, for instance, they may need to spell out in greater detail the potential benefits of the proposed actions, to assist investors in their task of sensitivity analysis. When the information-processing load in an industry is heavy, they may need to specifically address the heuristics that investors may use. Generally, the content of communication may need to include details that help investors to deal with the information-processing load associated with the relevant industry. Thus, we conclude that incorporating a cognitive perspective and applying a signaling framework to the event study literature leads to novel insights into the processes by which investors respond to corporate announcements.

\section{REFERENCES}

Auster, E. R. 1992. The relationship of industry evolution to patterns of technological linkages, joint ventures, and direct investment between U.S. and Japan. Management Science, 38: 778-792.

Baker, D. D., \& Cullen, J. B. 1993. Administrative reorganization and configurational context: The contingent effects of age, size, and change in size. Academy of Management Journal, 36: 1251-1277. 
Barry, C. B., \& Jennings, R. H. 1992. Information and diversity of analyst opinion. Journal of Financial and Quantitative Analysis, 27: 169-183.

Brennan, M., \& Kraus, A. 1987. Efficient financing under asymmetric information. Journal of Finance, 42: 1225-1243.

Bromiley, P., Govekar, M., \& Marcus, A. 1989. On using event-study methodology in strategic management research. In R. M. Burton, J. D. Forsyth, \& B. Obel (Eds.), Organizational responses to the new business conditions: An empirical perspective: 25-40. Amsterdam: Elsevier.

Bruning, J. L., \& Kintz, B. L. 1987. Computational handbook of statistics (3d ed.). Glenview, IL: Scott, Foresman.

Davidson, W. N., III, \& Worrell, D. L. 1992. The effect of product recall announcements on shareholder wealth. Strategic Management Journal, 3: 467-473.

Dess, G. G., Ireland, R. D., \& Hitt, M. A. 1990. Industry effects and strategic management research. Journal of Management, 16: 7-27.

Dodd, P., \& Warner, J. B. 1983. On corporate governance: A study of proxy contests. Journal of Financial Economics, 11: 401-438.

Dunbar, R. L. M. 1981. Designs for organizational control. In P. C. Nystrom \& W. H. Starbuck (Eds.), Handbook of organizational design, vol. 2: 85-115. New York: Oxford University Press.

Eisenhardt, K. M., \& Zbaracki, M. J. 1992. Strategic decision making. Strategic Management Journal, 13: 17-37.

Fama, E. F. 1976. Foundations of finance. New York: Basic Books.

Flynn, D. M. 1990. Intelligence for strategic decision making in multinational corporations. In G. S. Soukis, H. Conway, \& B. H. Charnov (Eds.), Global corporate intelligence: 93-108. New York: Quorum.

Fredrickson, J. W. 1984. The completeness of strategic decision processes: Extensions, observations, future directions, Academy of Management Journal, 27: 445-466.

Ghemawat, P. 1991. Commitment: The dynamic of strategy. New York: Free Press.

Hamel, G. 1991. Competition for competence and inter-partner learning within international strategic alliances. Strategic Management Journal, 12: 83-103.

Harrigan, K. R. 1985. Strategies for joint ventures. Lexington, MA: Lexington Books.

Harrigan, K. R. 1988a. Joint ventures and competitive strategy. Strategic Management Journal, 9: 141-158.

Harrigan, K. R. 1988b. Managing maturing businesses. Lexington, MA: Lexington Books.

Harrison, J. S., Hitt, M. A., Hoskisson, R. E., \& Ireland, R. D. 1991. Synergies and post-acquisition performance. Journal of Management, 17: 173-190.

Heil, O., \& Robertson, T. S. 1991. Toward a theory of competitive market signaling: A research agenda. Strategic Management Journal, 12: 403-418.

Higgins, R. B., \& Bannister, B. D. 1992. How corporate communication strategy affects share price. Long Range Planning, 25(3): 27-35.

Higgins, R. B., \& Diffenbach, J. 1989. Communicating corporate strategy: The payoffs and the risks. Long Range Planning, 22(3): 133-139.

Institutional Brokers Estimate System. 1992. Annotated bibliography: Earnings expectations research (4th ed.). New York: I/B/E/S Inc.

Koh, J., \& Venkatraman, J. 1991. Joint venture formations and stock market reactions: An assessment in the information technology sector. Academy of Management Journal, 34: 869-892. 
Lubatkin, M., \& Shrieves, R. E. 1986. Towards reconciliation of market performance measures to strategic management research. Academy of Management Review, 11: 497-512.

Maddigan, R. J. 1981. The measurement of vertical integration. Review of Economics and Statistics, 63: 328-335.

McConnell, J. J., \& Nantell, T. J. 1985. Corporate combinations and common stock returns: The case of joint ventures, Journal of Finance, 40: 519-536.

Miller, G. A. 1956. The magic number seven plus or minus two: Some limits to our capacity for processing information. Psychology Review, 50: 81-97.

O'Brien, P. C. 1990. Forecast accuracy of individual analysts in nine industries. Journal of Accounting Research, 28: 286-304.

Oliver, C. 1990. Determinants of interorganizational relationships: Integration and future directions. Academy of Management Review, 15: 241-265.

Prescott, J. E. 1986. Environments as moderators of the relationship between strategy and performance. Academy of Management Journal, 29: 329-346.

Reger, R. K., \& Huff, A. S. 1993. Strategic groups: A cognitive perspective. Strategic Management Journal, 14: 103-124.

Simon, H. A. 1957. Administrative behavior. New York: Macmillan.

Smith, K. G., \& Grimm, C. M. 1991. A communication-information model of competitive response timing. Journal of Management, 17: 5-23.

Spence, A. M. 1974. Market signaling. Cambridge, MA: Harvard University Press.

Taylor, R. N. 1984. Behavioral decision making. Glenview, IL: Scott, Foresman.

Tversky, A., \& Kahneman, D. 1974. Judgment under uncertainty: Heuristics and biases. Science, 185: 1124-1131.

Weick, K. E. 1970. The twigging of overload. In H. B. Pepinsky (Ed.), People and information: 67-129. New York: Pergamon.

Ravindranath (Ravi) Madhavan is a doctoral candidate in strategy, environment, and organization at the Katz Graduate School of Business, University of Pittsburgh. His research is based on a structural approach to strategy, bringing a network perspective to the study of strategic flexibility and core capability.

John E. Prescott is professor of business administration at the Katz Graduate School of Business, University of Pittsburgh. He received his Ph.D. degree from Pennsylvania State University. His research focuses on competitive intelligence, networks, and competitive dynamics. 
Copyright of Academy of Management Journal is the property of Academy of Management and its content may not be copied or emailed to multiple sites or posted to a listserv without the copyright holder's express written permission. However, users may print, download, or email articles for individual use. 